HIGH PRESSURE MERCURY VAPOUR LAMPS AND THEIR APPLICATIONS 
Distributors for The United Kingdom and Eire: CLEAVER-HUME PRESS LTD. (Macmillan \& Co LTD.) Little Essex Street, London, W.C. 2 


\section{HIGH PRESSURE MERCURY VAPOUR LAMPS AND THEIR APPLICATIONS}

W. ELENBAAS

J. B. DE BOER

TH. HEHENKAMP

CHR. MEYER

T. TOL

W. L. WANMAKER

M. H. A. VAN DE WEIJER

Edited by

W. ELENBAAS

1965

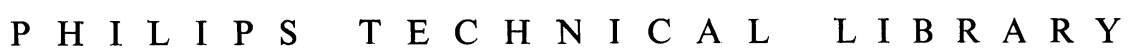


ISBN 978-1-349-81630-9 ISBN 978-1-349-81628-6 (eBook)

DOI $10.1007 / 978-1-349-81628-6$

This book will also be published in the French and German language

This book contains $\mathrm{XI}+304$ pages, 213 illustrations and 24 tables

U.D.C. 621.327 .534 .2

(C) N.V. Philips' Gloeilampenfabrieken, Eindhoven (The Netherlands), 1965

Softcover reprint of the hardcover 1st edition 1965 978-0-333-09136-4

All rights reserved

No representation or warranty is given that the matter treated in this book is free from patent rights; nothing herein should be interpreted as granting, by implication or otherwise, a licence under any patent rights 


\section{FOREWORD}

High pressure mercury vapour lamps have been used for a vast number of applications ever since their introduction in 1906. Among those applications is one of the most spectacular their use on an ever-increasing scale in public lighting systems.

Since 1951, when these and other gas-discharge lamps were discussed in a book by Funke and Oranje, published in this series, the Philips Light Group laboratories have made important contributions in the extension of the range of mercury vapour discharge lamps and the widening of their field of application.

In the present book, dealing with the whole field of high pressure mercury lamps in all their different forms and executions, the editor is fortunate to have had the assistance of six specialists, each of whom has contributed a chapter in his own special field covering a particular aspect of the subject. The complex character of this type of lamp is thereby amply demonstrated.

The level of treatment is such that no specialised knowledge is needed to understand the text, although certain sections are somewhat more complicated than others. These sections have been placed between asterisks and can be omitted if desired.

The latest addition to the high pressure mercury vapour discharge family, the iodide-discharge, is dealt with in an appendix.

This type of lamp is still in its infancy but promises to become very important indeed.

This is a high pressure mercury discharge to which one or more metal iodides have been added.

The authors wish to thank Mr. I.F. Davies for correcting the English version of the book. 


\section{CONTENTS}

W. ELENBAAS

FOREWORD V

INTRODUCTION . . . . . . . . . . . . . . . . . . 1

Chapter I: THE HIGH PRESSURE MERCURY VAPOUR DISCHARGE

1.1 Electric discharges in gases - general . . . . . . . . 5

1.2 High pressure mercury vapour discharges . . . . . . 8

1.3 The mechanism of the high pressure mercury vapour discharge . . . . . . . . . . . . . . . 10

1.4 The contraction of the discharge . . . . . . . . . . 14

1.5 The total radiation . . . . . . . . . . . . . . 16

1.6 The potential gradient formula . . . . . . . . . 21

1.7 The mercury vapour pressure. . . . . . . . . . 31

1.8 Temperature measurements . . . . . . . . . 32

1.9 Similar discharges . . . . . . . . . . . . . . 34

1.10 The spectrum. . . . . . . . . . . . . . . 38

1.11 The convection . . . . . . . . . . . . . . . . . 44

1.12 The influence of gases other than mercury . . . . . . 48

W. L. WANMAKER

Chapter II: FLUORESCENT MATERIALS

2.1 Luminescence, fluorescence, phosphorescence . . . . . 52

2.2 Activators . . . . . . . . . . . . . . 53

2.3 Phosphor emission . . . . . . . . . . . . . . . . 54

2.4 Requirements for high pressure mercury vapour lamp phosphors ................... . 56

2.5 Preparation of phosphors . . . . . . . . . . . . . 59

2.6 Some phosphors for high pressure mercury vapour lamps $\quad 60$ 2.6.1 Magnesium arsenate . . . . . . . . . . . . 60

2.6.2 Magnesium germanate . . . . . . . . . . 64

2.6.3 Tin-activated orthophosphates. . . . . . . . 66

2.7 Application of phosphors to high pressure mercury vapour lamps. . . . . . . . . . . . . . 68

TH. HEHENKAMP

\section{Chapter III: STABILIZATION}

3.1 Lamp characteristics . . . . . . . . . . 71 
3.2 Principle of stabilization _. . . . . . . . . . . 72

3.3 Shape of the lamp voltage on A.C. supplies . . . . 74

3.4 Basic forms of A.C. ballasts . . . . . . . . . . . . 76

3.5 Resistors as ballasts . . . . . . . . . . . . . . . 77

3.6 Calculation method with square-wave voltages . . . . 79

3.7 Inductors as ballasts. . . . . . . . . . . . . . . . 82

3.8 The capacitive ballast . . . . . . . . . . . . . . . 85

3.9 Influence of the losses . . . . . . . . . . . . . . . 90

3.10 Influence of saturation . . . . . . . . . . . . . . 91

3.11 Leak-transformers . . . . . . . . . . . . . . . . 92

3.12 Compensation . . . . . . . . . . . . . . . . . . 95

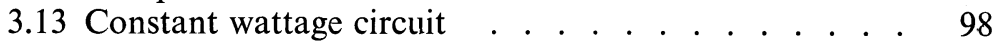

3.14 Constant current supply . . . . . . . . . . . . . . 100

3.15 Ballast construction . . . . . . . . . . . . . . . 103

3.16 Ballast mounting . . . . . . . . . . . . . . 105

M. H. A. VAN DE WEIJER

Chapter IV: HIGH PRESSURE MERCURY VAPOUR LAMPS FOR GENERAL LIGHTING PURPOSES

4.1 Description of the main types . . . . . . . . . . . 107

4.1.1 Lamps in which the visible light comes exclusively from the mercury discharge . . . . . . . . . 107

4.1.2 Lamps in which the ultraviolet radiation emitted by the mercury discharge is also used. . . . . . . 108

4.1.3 Lamps in which the light from the mercury discharge is coupled with that from a filament . . . 110

4.1.4 Lamps in which the light from the mercury discharge is coupled with fluorescent light and light from a filament . . . . . . . . . . . .

4.1.5 Lamp types with special light distribution characteristics. . . . . . . . . . . . 112

4.2 The discharge tube. . . . . . . . . . . . . . . 114

4.2.1 The material of the discharge tube . . . . . . . 115

4.2.2 The main electrode. . . . . . . . . . . . 116

4.2.2.1 The electrode shape and dimensions . . 117

a) The ignition time . . . . . . . . 117

b) The operating temperature . . . . . . 119

c) The emitter storage . . . . . . . . . 120

4.2.2.2 The emitter composition . . . . . . . . 121

4.2.2.3 The emitter weight . . . . . . . . . . . 122

4.2.2.4 The preparation and application of the emitter . . . . . . . . . 122

a) The dipped electrode . . . . . . . . 123

b) The pellet-electrode . . . . . . . 123

c) The thorium-electrode . . . . . . . 123 
4.2.3 The auxiliary electrode . . . . . . . . . . . . 124

4.2.4 The mercury and inert gas-filling in the discharge tube . . . . . . . . . . . . . . . . . . . . 124

4.2.4.1 The mercury dose . . . . . . . . . . 124

4.2.4.2 The inert gas-filling . . . . . . . . . . 125

4.2.5 The construction of the discharge tube . . . . . 128

4.2.6 Pumping the discharge tube . . . . . . . . . 129

4.3 The lamp construction . . . . . . . . . . . . 130

4.3.1 The ignition resistor . . . . . . . . . . . . . 130

4.3.2 The construction of high pressure mercury vapour lamps . . . . . . . . . . . . . . . . . 133

4.3.2.1 The outer-bulb . . . . . . . . . . . . 133

4.3.2.2 The fluorescent layer . . . . . . . . 135

4.3.2.3 The gas-filling in the outer-bulb . . . 136

4.3.2.4 The lamp-cap . . . . . . . . . . . . 138

4.3.3 The construction of blended light lamps. . . . . 138

4.3.3.1 The filament . . . . . . . . . . . . 138

4.3.3.2 The gas-filling in the outer-bulb . . . . . 140

4.3.3.3 The fluorescent coating on the inside of the outer-bulb ............ . 140

4.3.4 The construction of reflector lamps. . . . . . . . . 140

4.4 Luminous efficiency, light depreciation and life . . . . 142

4.4.1 The efficiency of high pressure mercury vapour lamps . . . . . . . . . . . . . . . . . . 142

4.4.2 The efficiency of blended light lamps . . . . . 143

4.4.3 Light depreciation resulting from the ignition process in the discharge tube. . . . . . . . . 143

4.4.4 Light depreciation as a result of cathode exhaustion .. . . . . . . . . . . . . . . . . . . 145

4.4.5 Light depreciation from the fluorescent coating in colour-corrected mercury lamps.

4.4.6 Light depreciation caused by the filament in blended light lamps . . . . . . . . . . . . . . . . . 146

4.4.7 The economic life of high pressure mercury vapour lamps . . . . . . . . . . . . . . . 146

4.4.8 The life of blended light lamps . . . . . . . . . 147

4.5 The behaviour of high pressure mercury vapour lamps during the run-up period and with mains voltage fluctuations .

4.5.1 The run-up period . . . . . . . . . . . . . . 147

4.5.2 Influence of mains voltage variations on high pressure mercury vapour lamps. . . . . . . . . . 148

4.5.3 Influence of mains voltage fluctuations on blended light lamps . . . . . . . . . . . . . . . 149

4.5.4 The extinction voltage . . . . . . . . . 152

4.5.5 The re-ignition time . . . . . . . . . . . . . 152

4.6 The spectral light distribution of high pressure mercury vapour lamps. . . . . . . . . . . . . . . . 
J. B. DE BOER

Chapter V: LIGHTING WITH HIGH PRESSURE MERCURY VAPOUR LAMPS

5.1 Introduction . . . . . . . . . . . . . . . . 158

5.2 The application possibilities suited as dictated by the light source properties . . . . . . . . . . . . . . 159

5.3 Special types of high pressure mercury vapour lamps . 171

5.3.1 Reflector lamps . . . . . . . . . . . . . . . 171

5.3.2 Blended light lamps . . . . . . . . . . . . . 173

5.4 Examples of lighting installations with high pressure mercury vapour lamps. . . . . . . . . . . . . . . 174

5.4.1 Applications in industry . . . . . . . . . . 175

5.4.2 Public lighting with high pressure mercury vapour lamps . . . . . . . . . . . . . 179

5.4.3 Some examples of installations of public lighting using high pressure mercury vapour lamps . . . . 188

5.4.4 Floodlighting and other special applications for high pressure mercury vapour lamps . . . . . . 194

T. TOL

Chapter VI: CONSTRUCTION AND APPLICATION OF HIGH PRESSURE MERCURY VAPOUR LAMPS FOR THE ULTRAVIOLET REGION

6.1 The spectrum of high pressure mercury vapour lamps in the U.V. region . . . . . . . . . . . . . . . . . . 203

6.2 Units of U.V. radiation . . . . . . . . . . . . . . 205

6.3 High pressure mercury vapour lamps for medical and cosmetic purposes . . . . . . . . . . . . . . . . 210

6.4 Irradiation lamps which are connected to the mains via a choke . . . . . . . . . . . . . . . 211

6.5 Irradiation lamps which are operated with a resistor ballast. . . . . . . . . . . . . . 216

6.6 High pressure mercury vapour lamps for photochemical applications . . . . . . . . . . . . . . . . . . . 223

6.7 The light-printing process . . . . . . . . . . . . . . . 224

6.8 Light-printing lamps . . . . . . . . . . . . . . . 225

6.9 A reflector lamp for application in reproduction and copying techniques . . . . . . . . . . . 232

6.10 High pressure mercury vapour lamps for fluorescent analysis ........... . . 235

CHR. MEYER AND T. TOL

Chapter VII: HIGH PRESSURE MERCURY VAPOUR LAMPS HAVING A HIGH LUMINANCE

7.1 Introduction . . . . . . . . . . . . . . . . . . . 240 
7.2 Some general aspects of high and super-high pressure mercury vapour discharges with a high luminance . .

7.3 The spherical high pressure mercury vapour lamp compact source lamp . . . . . . . . . . . . . . . 248

7.4 The electrodes of compact source lamps . . . . . . . 248

7.5 The current lead-in wires and seals of compact source lamps . . . . . . . . . . . . . . . 252

7.6 The bulb of compact source lamps . . . . . . . . . 255

7.7 Further constructional data and features of compact source lamps . . . . . . . . . . . . . . . . . . 258

7.8 The electrical operating conditions of compact source lamps . . . . . . . . . . . . . . . . 259

7.9 The ignition of compact source lamps . . . . . . . . 260

7.10 The run-up of compact source lamps . . . . . . . . 261

7.11 The operation of compact source lamps . . . . . . . 262

7.12 Ballasts for compact source lamps . . . . . . . . . 264

7.13 Survey of compact source lamps . . . . . . . . . . 265

7.14 The dimensions of a range of compact source lamps 266

7.15 The electrical and light technical data of some compact source lamps . . . . . . . . . . . . . . . . . . . . . . . 267

7.16 The luminance of compact source lamps . . . . . . . 268

7.17 Spectral energy distribution of compact source lamps. . 271

7.18 Applications of compact source lamps . . . . . . . 272

7.19 The capillary super-high pressure mercury vapour lamp 274

7.20 Dosed and over-dosed capillary super-high pressure mercury vapour lamps . . . . . . . . . . . . . . 275

7.21 The construction of capillary super-high pressure mercury vapour lamps . . . . . . . . . . . . . . . . . . . . 276

7.22 The electrical operating conditions of capillary superhigh pressure mercury vapour lamps . . . . . . . . 278

7.23 Ballasts for capillary super-high pressure mercury vapour lamps . . . . . . . . . . . . . . . . . . . . . . 278

7.24 Cooling of capillary super-high pressure mercury vapour lamps . . . . . . . . . . . . . . . 281

7.25 Data on some capillary super-high pressure mercury vapour lamps . . . . . . . . . . . . . . . . . . 284

7.26 Applications of capillary super-high pressure mercury vapour lamps . . . . . . . . . . . . . 285

7.27 The pulsed capillary super-high pressure mercury vapour lamp for film projection . . . . . . . . . . 288

7.28 Further improvements of the pulsed capillary super-high pressure mercury vapour lamps . . . . . . . . . 291

W. ELENBAAS

APPENDIX

IODIDE DISCHARGE LAMPS 